\title{
The efficacy of Nigella Sativa L extracts to reduce cardiovascular disease risk in diabetic dyslipidemia
}

Cite as: AIP Conference Proceedings 2120, 070020 (2019); https://doi.org/10.1063/1.5115737

Published Online: 03 July 2019

Retno Susilowati, Vikki Ainuzzakki, M. Rizqon Nadif, and Amalia Rizka Diana

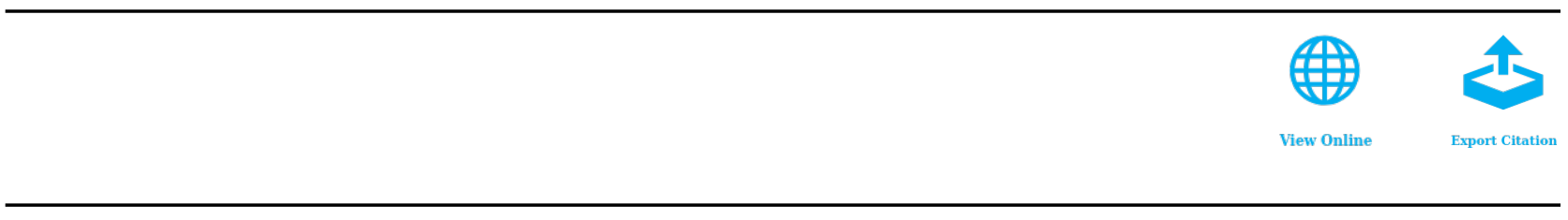

\section{Conference Proceedings}

Get $30 \%$ off all print proceedings!

\section{Enter Promotion Code PDF30 at checkout}




\title{
The Efficacy of Nigella Sativa L Extracts to Reduce Cardiovascular Disease Risk in Diabetic Dyslipidemia
}

\author{
Retno Susilowati ${ }^{1, a)}$, Vikki Ainuzzakki ${ }^{1, b)}$, M. Rizqon Nadif ${ }^{1, c^{c}}$ and Amalia \\ Rizka Diana ${ }^{1, d)}$
}

${ }^{1}$ Biology Departement of Science and Technology Faculty, State Islamic University of Maulana Malik Ibrahim Malang, Indonesia

${ }^{a}$ Corresponding author: retnosusilowatibms@gmail.com

bvikkiazz@gmail.com

rizqonjember@gmail.com

damalia.rizka94@gmail.com

\begin{abstract}
Diabetic diseases often witnessing complication with dyslipidemia that also easily experiencing status of oxidative stress. This study aimed to determine the potential of Nigella sativa L. seed extract in reducing lipoprotein serum and liver oxidative stress in diabetic dyslipidemia. Diabetic dyslipidemia rats were carried out by giving a high feed diet (HFD) for 14 weeks and injecting streptozotocin (STZ) at dose $30 \mathrm{mg} / \mathrm{kgbw}$ intraperitoneally once a week at the beginning of 9 th and 10th week. The treatments of Nigella sativa L. seed extracts were given between 11 th -14 th week. The ANOVA test showed that the Nigella sativa L. extract and metformin had a significant effect on LDL, HDL, and SOD levels. In addition, the DMRT test indicated that administration of the extract at the dose of 24-48 mg/kgbw was the most effective treatment in reducing LDL level, as well as in increasing HDL and SOD levels. The Kruskal Wallis test showed that the administration of Nigella sativa L. extract has effected on MDA level; furthermore, Mann Whitney test revealed that giving the extract at all doses were effective in reducing MDA. This effect met the standard of metformin drug until the animals got healthy again. It can be concluded that the antioxidant and hypolipidemic effects of Nigella sativa L. extract are potential in reducing the risk of cardiovascular disease in patients with diabetic hyperlipidemia.
\end{abstract}

\section{INTRODUCTION}

Complications of diabetes mellitus (DM) include coronary heart disease (CHD), stroke, peripheral arterial disease, nephropathy, retinopathy, and possibly neuropathy and cardiomyopathy. Thus, diabetes must take its place alongside the other major risk factors as the important causes of cardiovascular disease (CVD). The average borderline high systolic pressure of DM patients is $135 \pm 15 \mathrm{mmHg}$. From the point of view of cardiovascular medicine, it is appropriate to say that diabetes is a major risk factor of cardiovascular disease [1]. $40.6 \%$ of DM patients have been experiencing atherosclerotic cardiovascular for ten to 16 years and $59 \%$ of them possess multiple risks in suffering from atherosclerotic and cardiovascular diseases. People with a family history of type 2 DM would be more likely to experience CVD, CAD (33\%), PAD (6\%), CVD (7.6\%) and 10\% of heart failure. This shows that DM increases the risk of cardiovascular vary, which approximately, two to fourfold [2]. Moreover, vascular disease has been considered as the leading death cause among people with DM.

The high levels of LDL triglycerides specifically small dense LDL and low levels of HDL rich in triglycerides are often found in type 2 diabetic patients. Insulin resistance as use of type 2 diabetes weakens PI3-kinase, apoB degradation in hepatocytes and increased phospholipase D1 and ADP ribosylation factor 1 (ARF -1) increases the formation of VLDL. In addition, peripheral insulin resistance also increases lipolysis in adipose tissue into the hepatica port system so that it increases FFA so that it ultimately increases the production of VLDL and LDL. Hyperglycemic conditions also activate SREBP-1c (Sterol Regulatory Element-Binding Protein-1c), especially by Endoplasmic Reticulum stress which successfully increases de novo lipogenesis [3]. Furthermore, some of the 
metabolic syndromes associated with diabetes are the abnormalities in plasma lipoprotein production and clearance which led to diabetic dyslipidemia. The common symptoms of these conditions are the low amount or the decrease of high-density lipoprotein (HDL), raised triglycerides level, and postprandial lipemia. This is the most common pattern occurs in type 2 diabetes [4]. Glycosolated haemoglobin (HbAlc) as the only diabetes marker is positively correlated with TC, cLDL, TC/cHDL, TG/cHDL as considerable as negatively correlated with HDL-C, additionally, the glucose level is correlated with TG [5]. Literally, the common LDL cholesterol level of diabetes is "borderline high" (130-159 mg/dl). This can be assumed as the risk of diabetic cardiovascular. Notwithstanding that the small dense LDL (sdLDL) is more atherogenic compared to larger LDL particle, but it readily undergoes of oxidation and glycation enables this lipoprotein type for having high potential in damaging arterial wall [6].

Oxidative stress is often associated with both diabetic and hyperlipidemia conditions. Malondialdehyde (MDA) is a beneficial product of lipid peroxidation process as an oxidative stress marker. A double bound unsaturated lipid is a sensitive compound in responding to an oxidative attack and results in a final product with the MDA chain-like. The individual with type $2 \mathrm{DM}$ would be experiencing the increase of oxidative stress status, as considerable as the elevation of their MDA and oxLDL levels [7]. In other words, diabetic dyslipidemia and high oxidative stress are the risk factors need to be cured as an endeavor in avoiding cardiovascular disease which potentially occurred in diabetic patients. To date, there have been several compounds isolated, identified, and reported from different varieties of black cumin (Nigella sativa L.). The most important active compounds are thymoquinone, thymohydroquinone, dithymoquinone, thymol, and so forth [8]. Timoquinon includes essential oils from monoterpenoid ketone group Nigella sativa L [9]. Additionally, Bamosa et al. reported that black cumin at a dose of $2 \mathrm{gr} /$ day had significantly decreased the levels of Fasting Blood Glucose (FBG), 2-hour Postprandial Glucose (2hPG), and Hemoglobin A1 (HbA1) [10]. Kaatabi et al. findings revealed that Nigella sativa L. seeds supplementation at a dose of $2 \mathrm{~g}$ /day for 12 weeks has improved the dyslipidemia-associated with type 2 diabetic patients [11]. However, a little different conclusion was stated by George et al.' his team reported that Nigella sativa L. oil treatment at a dose of $1 \mathrm{ml} / \mathrm{kgbw}$ which was given to the hyperlipidemic mice, which were induced with monosodium glutamate of $0.8 \mathrm{mg} / \mathrm{kgbw}$, for 28 days have decreased the lipid just in case it is given along with astaxatin [12]. Thus, the hypolipidemic effect of Nigella sativa L. on diabetic hyperlipidemia is still needed to confirm.

Some previous researches which observed Nigella sativa L. as an antioxidant for diabetes have also resulted in various findings. Desai et al. found that nigella powder at the dose of $300 \mathrm{mg} / \mathrm{kgbw}$ has significantly diminished MDA as significant as escalated SOD level in diabetic albino mice even though it was not at the normal stage [13]. On the other hand, Hadi et al. also revealed that the treatment of $500 \mathrm{mg}$ of Nigella sativa L. oil per day for eight weeks has decreased MDA serum and NO albeit has no significant in increasing SOD enzymatic antioxidant and catalase [14].

This current research aimed at obtaining the maximum effective dose of single ethanol extract of Nigella sativa L. to improve lipid profile and oxidative stress status in type 2 DM rats as an effort in declining the Cardio Vascular Disease risk factors in diabetic dyslipidemia for maintaining optimum health.

\section{EXPERIMENTAL DETAILS}

\section{Diabetic Dyslipidemia Induction}

The research was carried out by using Rattus norvegicus Wistar strain as the animal model. It was limited that the animal ages were between three and four months with the body weight range between 150 and $200 \mathrm{~g}$. The animals were obtained from the Integrated Research and Testing Laboratory at Gadjah Mada University, Yogyakarta. The animal models were treated with high-fat diet (HFD) which contained $33 \%$ cow fat, not including the negative control group [15]. They were also given ad-libitum for ten weeks after 2-week acclimation as well as given 40g HFD food for each individual. All individual was induced with streptozotocin (STZ, from Merck) intraperitoneally at a low dose $(30 \mathrm{mg} / \mathrm{kgbw}$ in 0.1 citrate-buffered saline $\mathrm{pH} 4.5$ in the first day of week nine and ten) by excluding the negative control group. After the fifth day of STZ treatment, the measurement of blood fasting glucose level was conducted. The level of normal rats was approximately $100 \mathrm{mg} / \mathrm{dl}$; meanwhile, the tested diabetic rats used in this research was above $200 \mathrm{mg} / \mathrm{dl}$. 


\section{Extraction}

As much as $120 \mathrm{~g}$ of Indonesian black cumin (Nigella sativa $\mathrm{L}$.) seeds were obtained from Balitro, Bogor. The seeds then were dried in the temperature of $\pm 40{ }^{\circ} \mathrm{C}$ using an oven for $2 \times 24 \mathrm{~h}$, and ground using a blender. The seed powder was then sifted using 60 mesh size sieve. As the smooth and uniformed Nigella sativa L. seed powder gained, the extraction was done. The extraction was started with the maceration process using $80 \%$ ethanol as the solvent. Every $60 \mathrm{~g}$ of Nigella sativa L. seed powder was immersed in $300 \mathrm{ml}$ ethanol for $2 \times 24 \mathrm{~h}$ and placed in a shaker for three hours which was then filtered. The obtained filtrate then be concentrated using rotary evaporator.

\section{Treatment and Sampling}

This research was conducted using Complete Block randomized Design. By excluding non-diabetic dyslipidemia (normal, $\mathrm{nDdL}$ ), diabetic dyslipidemia (DdL) rats were grouped into five treatments (four replications): DdL rats with Nigella sativa extract treatments at doses $0 \mathrm{mg} / \mathrm{kgbw}$ (DdLNs-0), $24 \mathrm{mg} / \mathrm{kgbw}$ (DdLNs-24), $48 \mathrm{mg} / \mathrm{kgbw}$ (DdLNs-48), $72 \mathrm{mg} / \mathrm{kgbw}$ (DdLNs-72), as well as the group with metformin treatment at a dose of $45 \mathrm{mg} / \mathrm{kgbw}$ (DdLMetf). 0.5\% CMC solution was used to dissolve the extract and also a placebo treatment. As much as $2.5 \mathrm{ml}$ extract was given per rats per day using the feeding tube for four weeks.

At the end of the research, animal models have treated fasting, cervical dislocation, and terminal surgery. Following the previous procedures, blood and liver isolations were done immediately. The blood serum was isolated from the heart organ. The blood obtained was centrifuged in $3000 \mathrm{rpm}$ for $15 \mathrm{~min}$. The blood serum was stored in $20{ }^{\circ} \mathrm{C}$ before observation was conducted. A number of $0.1 \mathrm{~g}$ liver was ground and added with $0.9 \% \mathrm{NaCl}$ which then the homogenate was replaced in a micro tube and centrifuged in $8000 \mathrm{rpm}$ for $20 \mathrm{~min}$ until the clear lysate was obtained. The measurements of SOD and MDA levels were then immediately done.

\section{Data Collection}

The glucose level was measured using the Blood Glucose Test Meter GlucoDr (Accu Check) after treating the rats with fasting for eight hours. The total cholesterol (TC), direct cholesterol-HDL (cHDL), direct cholesterol-LDL, and triglycerides (TG) were tested using the colorimetric method by following the procedure defined by the instrument and reagent product supplier from Biosystem, Co. The observation was done using blood analyzer spectrophotometer at $\lambda 500 \mathrm{~nm}$. Meanwhile, the measurement of liver MDA level was conducted based on Thiobarbituric Acid (TBA) method by following the procedure provided by the MDA determination kit from Sigma Aldrich in which the wavelength setting was $\lambda 532 \mathrm{~nm}$. Furthermore, the SOD activity measurement was carried out using nitroblue tetrazolium (NBT) under SOD determination kit (from Merck) procedure in which the wavelength setting was $\lambda 440 \mathrm{~nm}$.

\section{Statistical Analysis}

The glucose measurement results were analyzed descriptively. Moreover, the lipid profile and SOD data which met the normal distribution and homogeneity of variance were analyzed using one-way ANOVA and DMRT 5\% to test the effect of the treatments given. However, the MDA data which normally distributed but the variance was not homogeny, the non-parametric tests were performed to test the effect of the given treatment. The tests were KruskalWallis which was continued to Post Hoc Multiple Comparisons using U-Mann-Whitney 5\% test.

\section{RESULTS AND DISCUSSION}

The research results showed that the treatments of HFD for ten weeks and STZ was succeeded in altering the animal models into diabetic dyslipidemia condition. Compared to the normal (nDdL) group, diabetic dyslipidemia (DdLNs-0) rats group has significantly experienced the elevation of blood sugar level from $91.00 \pm 3.1 \mathrm{mg} / \mathrm{dl}$ to $200 \mathrm{mg} / \mathrm{dl}-476 \mathrm{mg} / \mathrm{dl}$, the increase of cLDL level from $8.75 \pm 0.96 \mathrm{mg} / \mathrm{dl}$ to $13.00 \pm 2.94 \mathrm{mg} / \mathrm{dl}$ and also the reduction of cHDL level from $40.5 \pm 2.38 \mathrm{mg} / \mathrm{dl}$ to $21.75 \pm 1.71 \mathrm{mg} / \mathrm{dl}$. In addition, the treatments of Indonesian Nigella sativa L. extracted with alcohol $80 \%$ were unable to improve the total cholesterol level and triglycerides albeit at the dose 24$48 \mathrm{mg} / \mathrm{kgbw}$ were significantly decreased the cLDL as significant as upsurged the cHDL level. Moreover, the 
treatment at that dose has also increased the oxidative stress level and decreased the MDA level as well as elevated SOD level in rats liver, which equals to those level of normal rats and the treatment with metformin (Table 1).

TABLE 1. The analysis results of the lipid profile in blood serum of experimental rats

\begin{tabular}{|c|c|c|c|c|c|c|c|}
\hline \multirow[t]{2}{*}{ Parameters } & \multicolumn{6}{|c|}{ Treatments } & \multirow{2}{*}{$\begin{array}{l}\text { Anova } \\
\text { Test }\end{array}$} \\
\hline & nDdLNs & DdLNs-0 & DdLNs-24 & DdLNs-48 & DdLNs-72 & DdLMetf & \\
\hline \multicolumn{8}{|l|}{ Serum } \\
\hline $\mathrm{TC}(\mathrm{mg} / \mathrm{dl})$ & $46.25 \pm 3.63$ & $63.5 \pm 15.90$ & $57.25 \pm 19.15$ & $41.25 \pm 7.46$ & $47.75 \pm 15.04$ & $48.25 \pm 8.98$ & $\mathrm{P}>0.05$ \\
\hline TG (mg/dl) & $53.5 \pm 11.28$ & $78.00 \pm 42.50$ & $70.25 \pm 19.32$ & $39.75 \pm 13.53$ & $44.75 \pm 16.53$ & $60.5 \pm 19.46$ & $\mathrm{P}>0.05$ \\
\hline $\begin{array}{c}\mathrm{LDL} \\
(\mathrm{mg} / \mathrm{dl})\end{array}$ & $8.75 \pm 0.96^{\mathrm{a}}$ & $13.00 \pm 2.94^{\mathrm{b}}$ & $10.50 \pm 3.32^{\mathrm{ab}}$ & $8.0 \pm 0.82^{\mathrm{a}}$ & $11.50 \pm 2.52^{\mathrm{ab}}$ & $8.50 \pm 1.73^{\mathrm{a}}$ & $\mathrm{P}<0.05$ \\
\hline $\begin{array}{r}\text { HDL } \\
(\mathrm{mg} / \mathrm{dl})\end{array}$ & $40.5 \pm 2.38^{\mathrm{bc}}$ & $21.75 \pm 1.71^{\mathrm{a}}$ & $34.25 \pm 5.68^{b}$ & $55.50 \pm 1.71^{\mathrm{d}}$ & $43.50 \pm 9.75^{c}$ & $38.75 \pm 4.43^{\mathrm{bc}}$ & $\mathrm{P}<0.05$ \\
\hline \multicolumn{8}{|l|}{ Hepar } \\
\hline $\mathrm{SOD}(\mathrm{U} / \mathrm{ml})$ & $7.30 \pm 0.62^{\mathrm{b}}$ & $3.57 \pm 0.82^{\mathrm{a}}$ & $6.21 \pm 0.80^{\mathrm{b}}$ & $6.69 \pm 1.48^{\mathrm{b}}$ & $6.03 \pm 1.46^{\mathrm{b}}$ & $7.12 \pm 1.26^{\mathrm{b}}$ & $\mathrm{P}<0.05$ \\
\hline $\begin{array}{r}\mathrm{MDA}^{\ddagger} \\
(\mathrm{ng} / \mathrm{ml})\end{array}$ & $1266.50 \pm 30.97^{b}$ & $1389.63 \pm 71.49^{c}$ & $840.25 \pm 321.23^{\mathrm{a}}$ & a $773.38 \pm 274.75^{\mathrm{a}}$ & $846.50 \pm 326.42^{\mathrm{a}}$ & $832.75 \pm 313.02^{\mathrm{a}}$ & $\mathrm{P}<0.05^{\S}$ \\
\hline
\end{tabular}

Note: nDdL: normal mice, non-diabetic dyslipidemia; DdLNs-0: DdL rats without extract and medicine; DdLNs-24: DdL rats treated at extract dose of $24 \mathrm{mg} / \mathrm{kgbw}$; DdLNs-48: DdL rats treated at an extract dose of $48 \mathrm{mg} / \mathrm{kgbw}$; DdLNs-72: DdLNs rats treated at extract dose of $72 \mathrm{mg} / \mathrm{kgbw}$; DdLNsMetf: DdLNs rats treated at metformin dose $3.6 \mathrm{mg} / \mathrm{kgbw}$; the means followed by the different alphabets in the same line show a significant difference in DMRT test with $\alpha=0.05$; $\S$ significance in KruskalWallis; $\neq$ means which are followed by the different alphabet in the same line indicates the significant difference in MannWhitney test.

The addition of 33\% lipid in rats BRI food for nine weeks and the STZ injection at the twofold doses in the last two weeks i.e. $2 \times 30 \mathrm{mg} / \mathrm{kgbw}$ (DdLNs-0) has induced the significant increase of LDL level as high as $48.6 \%$ and decreased HDL of $45.7 \%$. Likewise, the treatments of Nigella sativa L. extracted with $80 \%$ alcohol for five weeks in this research were enable in diminishing LDLc as much as 38.5\% and escalating cHDL for approximately $63.0 \%$ to $114 \%$ (DdLNs-24 and DdLNs-48).

These results are in line with some previous research findings in which the treatment was giving Nigella sativa L in the form of seed powder. The consumption of Nigella sativa L seed was a gram per day for 30 days. This treatment had decreased TC, TG, LDL, and increasing HDL [16]. It is still in accordance with those findings, Pourghassem-Gargari et al. reported that the Nigella sativa L. powder treatment at dose $7.5 \mathrm{~g} / \mathrm{kgbw} / \mathrm{day}$ and the crushed Nigella sativa L. seed added with $0.5 \%$ cholesterol rabbit diet treatment given for two months each have significantly decreased LDL and increased HDL [17]. Besides that, feeding treatment added with 5\% Nigella sativa L. oil for seven weeks has significantly reduced LDL and raised HDL serum [18].

Compared to the other researches which observed Nigella sativa L. treatments, the findings of this research are better. The researches mentioned were the consumption of two teaspoons of Nigella sativa L. seeds after eating for 28 days has increased HDL of 11.94\% [19]. Giving Nigella sativa L. oil for 12 weeks has elevated cHDL as much as $19 \%$ and decreased cLDL about $17.6 \%$ [20]. The diminished of cLDL by the Nigella sativa L. extract is supporting Ahmad \& Beg's findings which proved that either methanol extract or volatile oil are able to decrease the enzymatic activity of HMG-CoA reductase, the mevalonic acid and cholesterol forming are inhibited [21]. On the other hand, Nigella sativa L seed and oil-rich of polyunsaturated fatty acids (PUFA) and monounsaturated fatty acids (MUFA) [22]. Replacement of SFA intake with MUFA can reduce total cholesterol and LDL cholesterol without lowering HDL cholesterol. Therefore, this condition can improve the ratio of LDL: HDL cholesterol, an atherosclerosis index [23].

The total cholesterol and triglycerides in the animal models used in this research were still at normal levels. This means that the Nigella sativa L. extract did not decrease this lipoprotein significantly. The findings are supported by Ati et al. who found that the treatment of Nigella sativa $\mathrm{L}$. at dose $2.5 \mathrm{~g} / 100 \mathrm{~g}$ food ( $300 \mathrm{~g}$ of food per day) in normal rabbit for four weeks did not effect TC and TG. This indicated that Nigella sativa L. extract was safe to be consumed by a healthy individual [24].

The induction of diabetic hyperlipidemia in animal models in this research has increased oxidative stress, MDA as of $9.7 \%$ and decreased SOD as of $5.1 \%$ (DdLNs-0). Besides that, the treatments given were also able to improve the oxidative stress status of hepar tissue, increasing SOD about 73.9\%-87.4\% (DdLNs-24 and DdLNs-48), as well as decreasing MDA for approximately 39.5\%-44.3\% (DdLNs-48 and DdLNs-24). This is in line with the research report of Pourghassem-Gargari et al. who reported that the Nigella sativa L. powder treatments at dose 7.5 $\mathrm{g} / \mathrm{kgbw} /$ day and the crushed Nigella sativa L. seed added with $0.5 \%$ cholesterol rabbit diet treatment is given for two 
months each has significantly decreased MDA [17]. This was assumed that the conditions were caused by the thymoquinone activity within the nigella extract. Majed et al. stated that the pretreatment of ischemic rats with thymoquinone has decreased the elevated levels of malondialdehyde and increased GSH contents, catalase, and SOD activities to normal level [25].

Nuclear respiratory factor 2 alpha subunit (NRF2), transcription factor NRF2 controls genes encoding phase 2 detoxifying enzymes and antioxidant proteins [26]. The thymoquinone treatment in Cisplatin caused significant down-regulation of the nuclear NF-E2-related factor-2 (NRF2) which is the key molecule of the endogenous antioxidant system [27]. In NRF2 signalling in activating defensive gene which is mediated by ARE, NRF2 regulates antioxidant gene expression to increase the expression and SOD gene translation [28]. This elaborates the way of Nigella sativa L. extracted with ethanol is able to escalate SOD level significantly as the findings of this research.

The Superoxide dismutase (SOD) as one of the antioxidant enzyme function to protects cells from ROS bad effects. SOD functions in catalyzing superoxide $\left(\mathrm{O}_{2}^{-}\right)$radical dismutation into hydrogen peroxide $\left(\mathrm{H}_{2} \mathrm{O}_{2}\right)$ which, in turn, the hydrogen peroxide can be degraded by an enzyme such as catalase into oxygen molecular products either the stable $\mathrm{O}_{2}$ or $\mathrm{H}_{2} \mathrm{O}$. Therefore, the high SOD indicates the decrease of oxidative stress which leads to the inhibition of MDA forming in this research.

\section{SUMMARY}

Nigella sativa L. has been proven to be antidiabetic medicine, this research confirmed its potential in reducing CVDs risk in diabetic dyslipidemia. The findings of this research proved that the black cumin seed extract decreased the risk factors of atherosclerosis in diabetic dyslipidemia by improving lipid profile as well as the oxidative stress, diminishing LDL and MDA levels and increasing HDL and SOD levels.

\section{ACKNOWLEDGEMENT}

The author expresses his gratitude to the Faculty of Science and Technology for financial research support.

\section{REFERENCES}

1. R. G. Miller, T. Costacou and T. J. Orchard, Diabetes 68(2), 409-419 (2019)

2. S. D. Wiviott, I. Raz, M. P. Bonaca, O. Mosenzon, E. T. Kato, A. Cahn, M. G. Silverman, T. A. Zelniker, J. F. Kuder, S. A. Murphy, D. L. Bhatt, L. A. Leiter, D. K. McGuire, J. P. H. Wilding, C. T. Ruff, I. A. M. Gause-Nilsson, M. Fredriksson, P. A. Johansson, A. M. Langkilde and M. S. N Engl. J. Med. 380, 347-357 (2019).

3. B. Vergès, Atherosclerosis 211(2), 353-360 (2010).

4. I. J. Goldberg, JCEM 86(3), 965-971 (2001).

5. R. N. Das, Diabetes Manag. 7(2), 247-249 (2017).

6. R. W. Nesto, Clin. Diabetes, 26 (1), 8-13 (2008).

7. F.A. Ganjifrockwala, J. T. Joseph \& G. George, J. EndocrinoL, 22(2), 21-25 (2017).

8. A. M. Yessuf, AJLS, 3(5), 358-364 (2015).

9. B. Nickavara, F. Mojaba, K. Javidniab, and M. A. R. Amolia, Z. Naturforsc 58 (c), 629-632 (2003)

10. A.O. Bamosa, H. Kaatabi, F. M. Lebdaa, A. M. Elq and A. Al-Sultan, Indian J. Physiol. Pharmacol. 54(4), 34454 (2010).

11. H. Kaatabi, A. O. Bamosa, F. M. Lebda, A. H. Al-Elq and A. I. Al-Sultan, J. Fam. Community. Med. 19(3), 155-161 (2012).

12. B. George and B. Kumaran, Int. Arch. App. Sci. Technol. 6, 01- 07 (2015).

13. S. D. Desai, S. H. Saheb, K. K. Das, S. Haseena, J. Pharm. Sci. \& Res. 7(4), 206-209 (2015).

14. V. Hadi, S. Kheirouri, M. Alizadeh, A. Khabbazi, H. Hosseini, AJP, 6 (1), 34-43 (2016).

15. M. Zhang, Xiao-Yan Lv, J. Li, Zhi-Gang Xu and Li Chen, Exp. Diabetes Res. 2008, 1-9 (2008).

16. I. Bhatti, S. Inayat, B. Uzair, F. Menaa, S. Bakhsh, H. Khan, F. Naz and B. A. Khan, IJPER, 50 (3), (2016).

17. B. Pourghassem-Gargari1, V. Ebrahimzadeh-Attary, M. Rafraf and A. Gorbani, J. Med. Plants Res. 3(10), 815-821 (2009).

18. A. Al-Logmani, T. Zari, J. Diabetes Mellitus 1(3), 46-53 (2011). 
19. A. Fatima, M. N. Shad, A. Asrar and S. Murad, P J M H S 8(1), 122-124 (2014).

20. J. Heshmati, N. Namazi, M. R. Memarzadeh, M. Taghizadeh and F. Kolahdooz, Food Res. Int. 70, 87-93 (2015).

21. S. Ahmad and Z. H. Beg, Lipids Health and Dis., 12 (86), 1-12 (2013).

22. H. Haron, C. Grace-Lynn and S. Shahar, Sains Malaysiana 43(4), 535-542 (2014).

23. P. M. Kris-Etherton, T. A. Pearson, Y. W. Wan, R. H. L. Hargrove, K. Moriarty, V. Fishell and T. D. Etherton, Am. J. Clin. Nutr. 70, 1009-1015 (1999).

24. K. A. A. Ati, A. E. Mustafa and H. E. Mohamed, J. Anim. Sci. 3 (3), 227 - 230 (2009).

25. A. A. Al-Majed, F. A. Al-Omar and M. N. Nagi, Eur. J. Pharmacol. 543, 40-47(2006).

26. Z. Yu, W. Shao, Y. Chiang, W. Foltz, Z. Zhang, W. Ling, I. G. Fantus and T. Jin, Diabetologia 54, $922-934$ (2011).

27. R. Ulu, A. Doğukan, M. Tuzcu, A. Gurel, I. Muqbil, R. M. Mohammad and K. Sahin, Turk Neph. Dial. Transpl. 22(2), 182-187 (2013).

28. J. W. Kaspar, S. K. Niture and A. K. Jaiswal, Free Radic. Biol. Med. 47, 1304-1309 (2009). 